\title{
Emerging Contaminants in
}

Urban Environments:

From Leaking Sewers to

Nanoparticles in Concrete

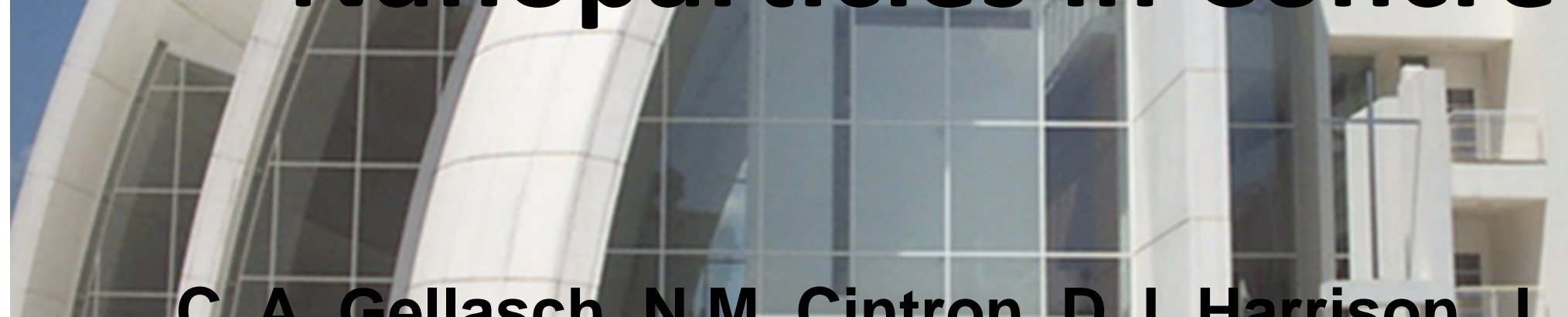

C. A. Gellasch, N.M. Cintron, D.J. Harrison, J. Honey, I A. Aisher, and A.R. Poda

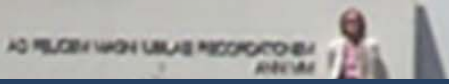

25 September 2016 Geological Society of America Annual Meeting 


\section{DISCLAIMER}

The views expressed are those of the author and do not necessarily reflect the official views of the Uniformed Services

University of the Health Sciences, the U.S. Army, or the Department of Defense.
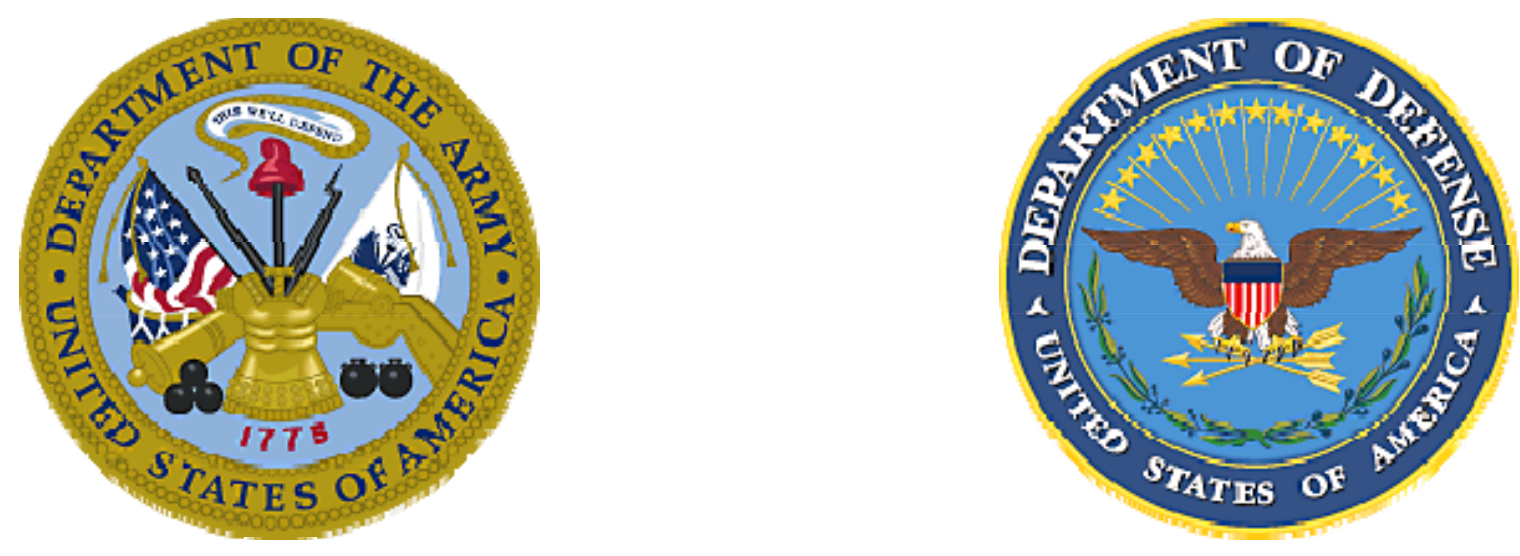


\section{INTRODUCTION}

\section{Emerging Contaminants}

- Urban areas

- Sewers (old)

- Concrete (new)

- Roads

- Buildings

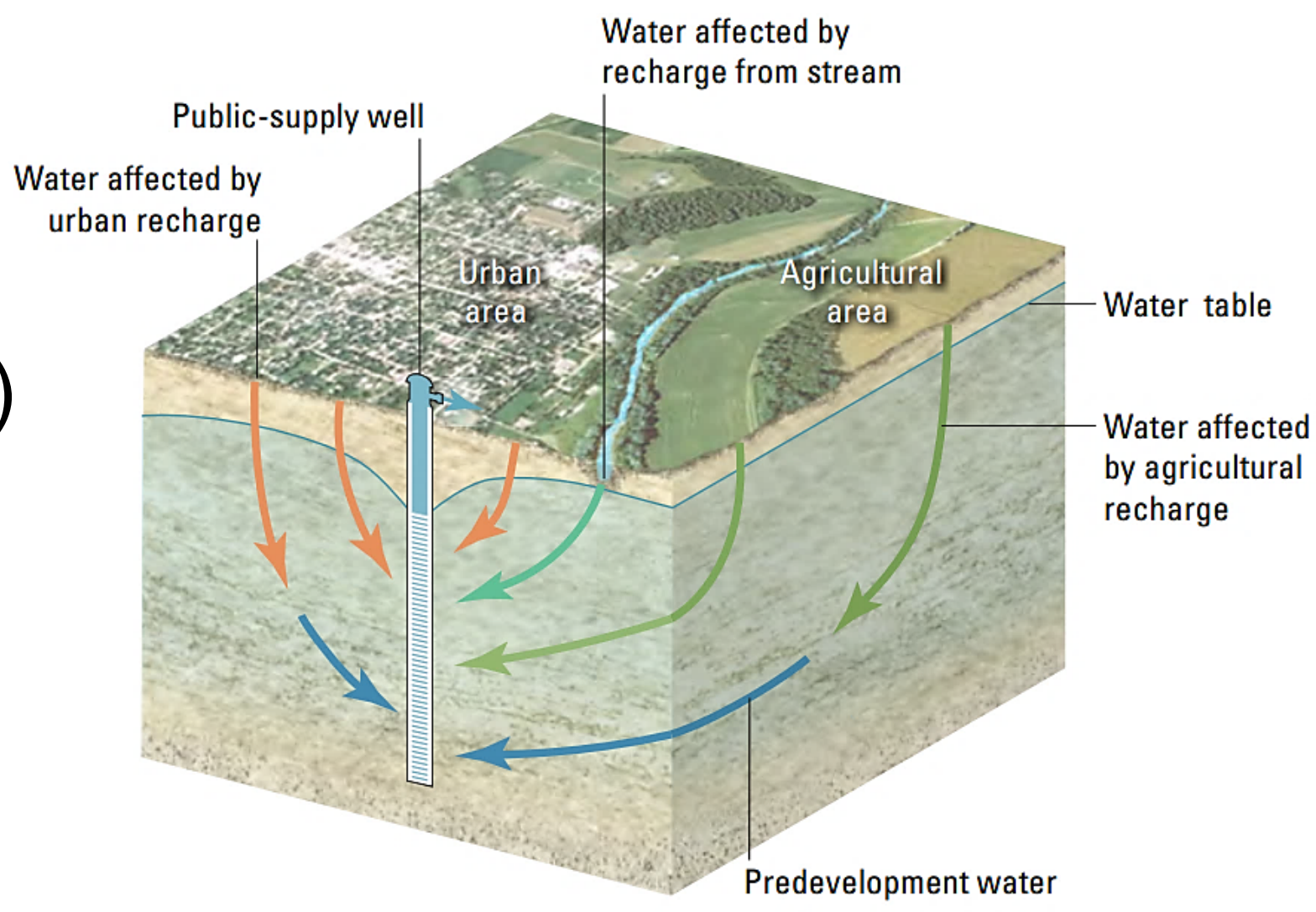




\section{INTRODUCTION}

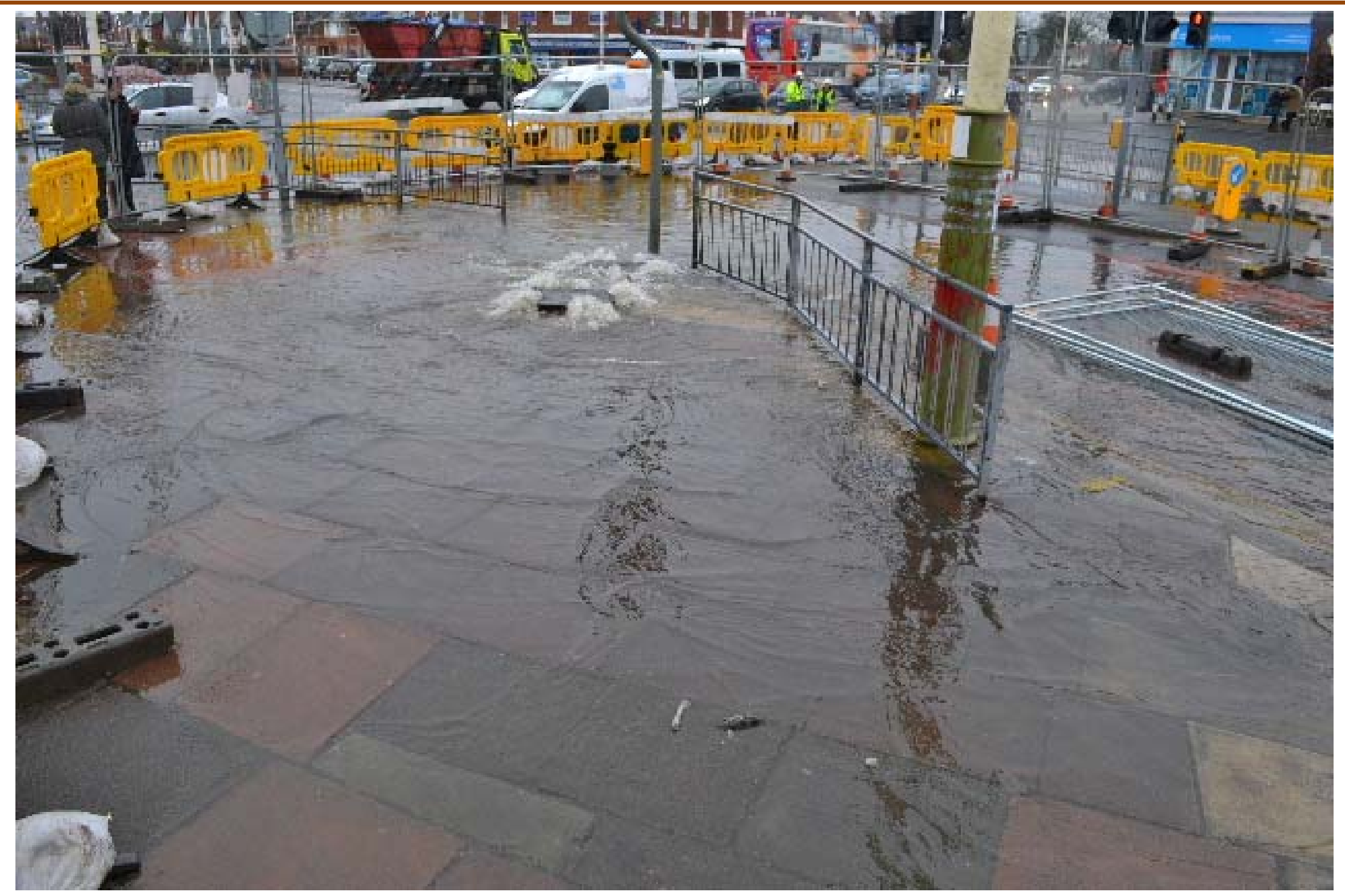




\section{LEAKING SEWERS}

- Leakage rate

-0.01 to $0.1 \mathrm{~L} / \mathrm{sec} / \mathrm{km}$

$-10 \%$ to $50 \%$ of total flow

- Pharmaceuticals

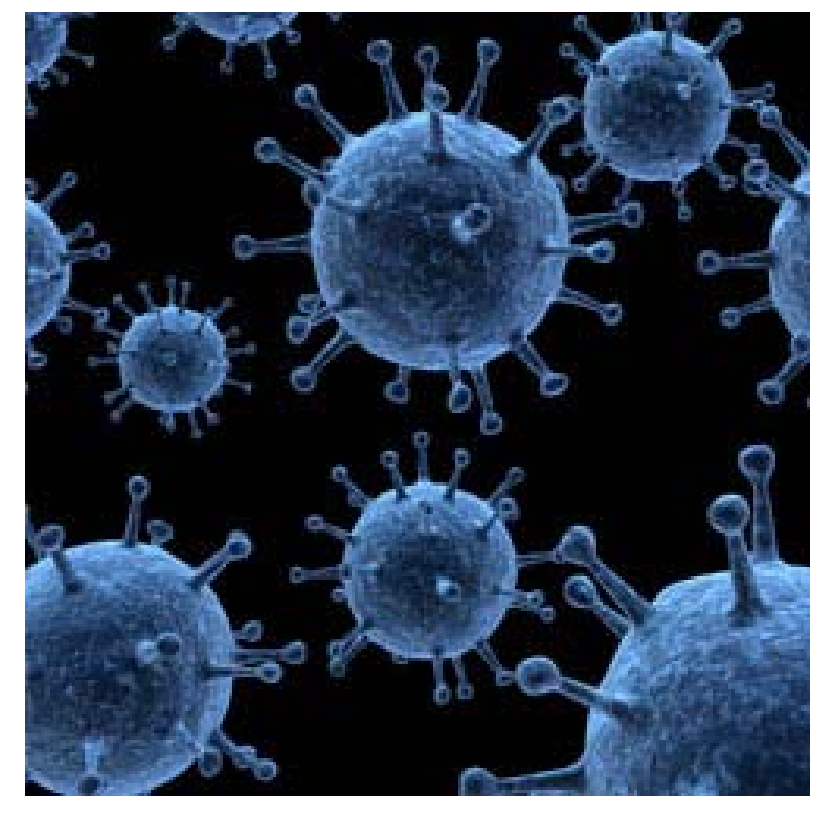

- Human enteric viruses in water

Norovirus

- Only source is human waste 


\section{MADISON, WI STUDY}

- Virus detection

- All monitoring wells

- Public supply well

- Sewers likely source

- Rapid transport to lower aquifer

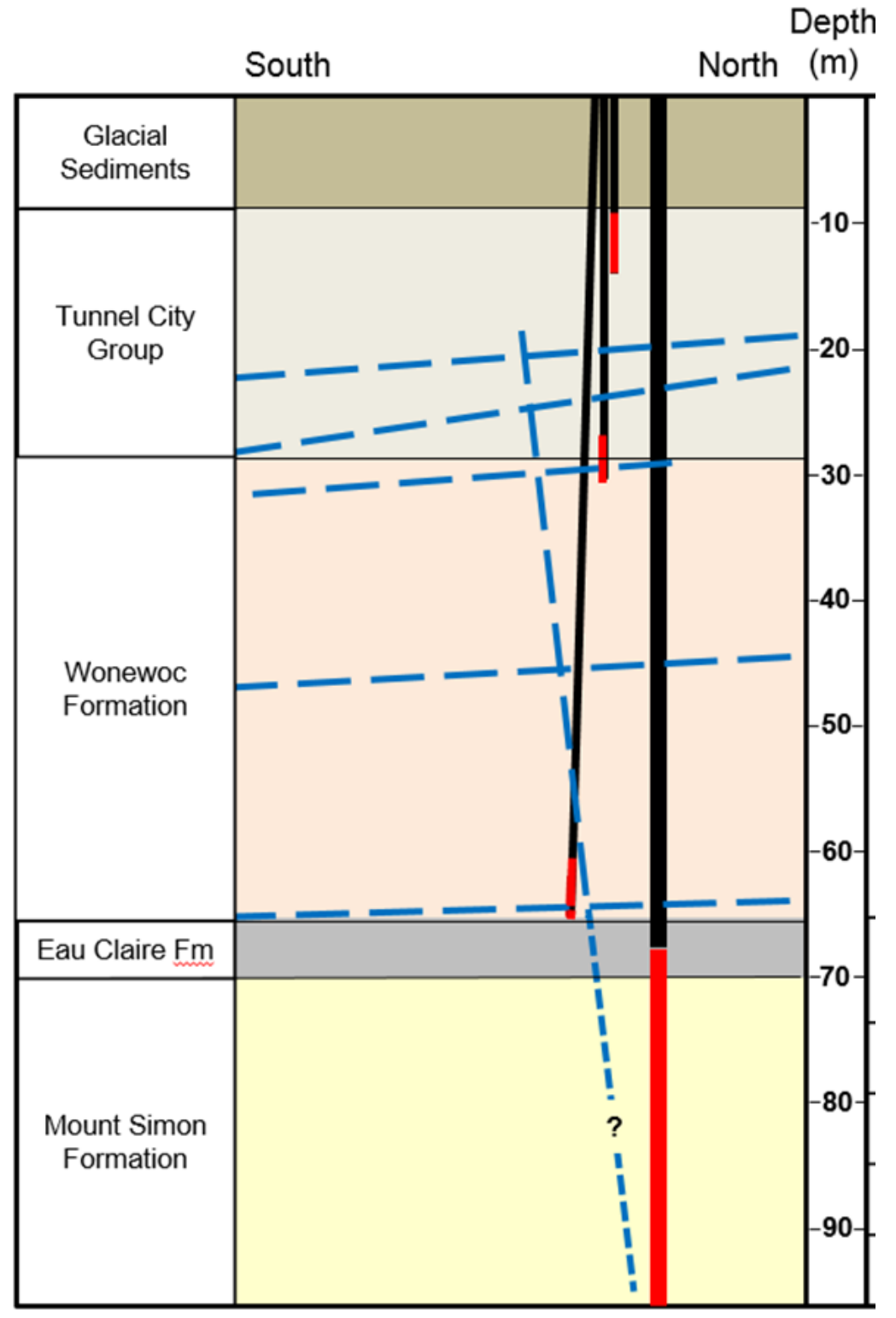




\section{ROCK CREEK STUDY}

- Mixed-use watershed

- Maryland and DC

- Rural to urban

- Sewer density and age (GIS)

- Creek sampling

- E. coli

- Nutrients ( $\mathrm{N}$ and $\mathrm{P}$ )

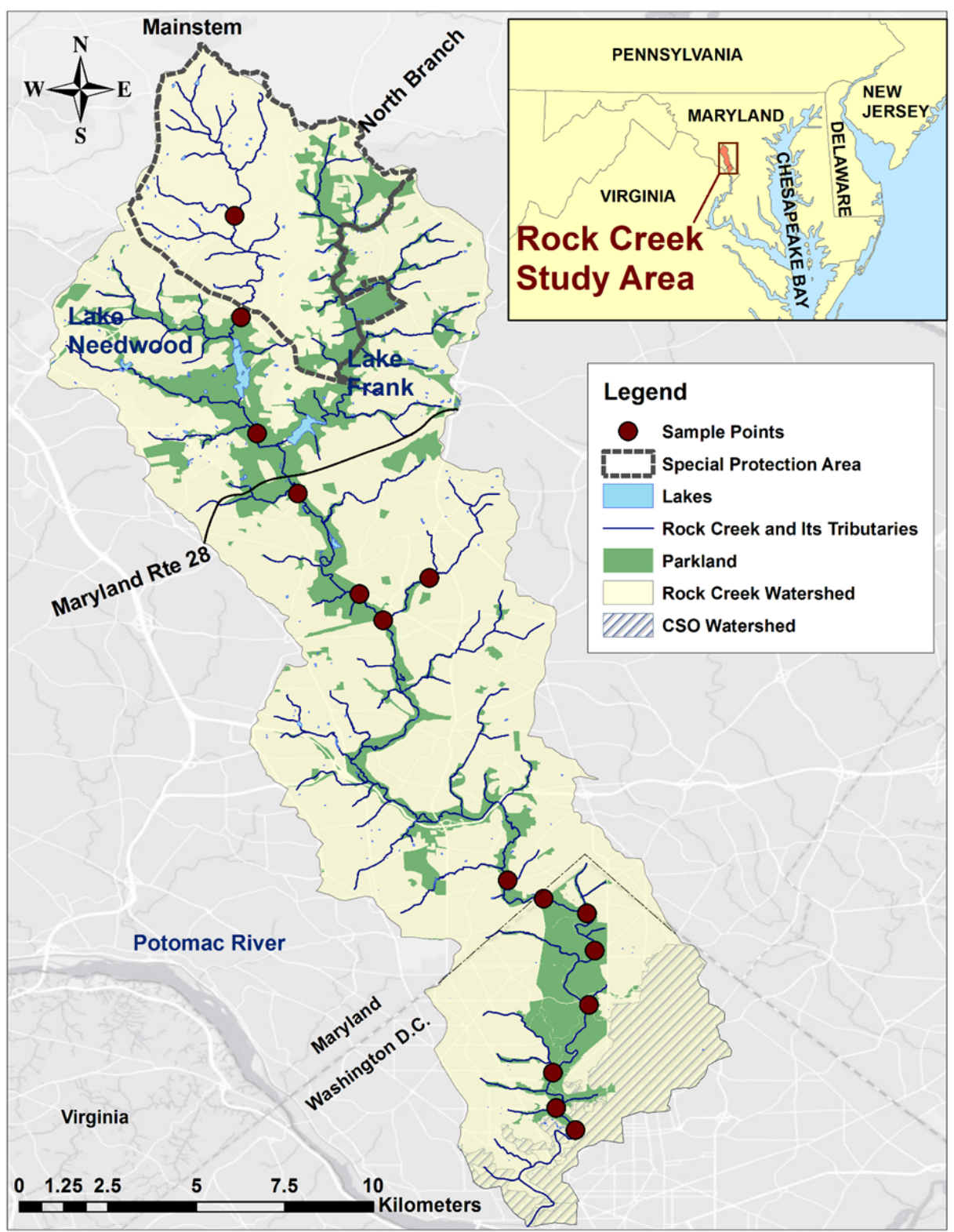




\section{ROCK CREEK STUDY}

- Mixed-use watershed

- Maryland and DC

- Rural to urban

- Sewer density and age (GIS)

- Creek sampling

- E. coli

- Nutrients ( $\mathrm{N}$ and $\mathrm{P}$ )

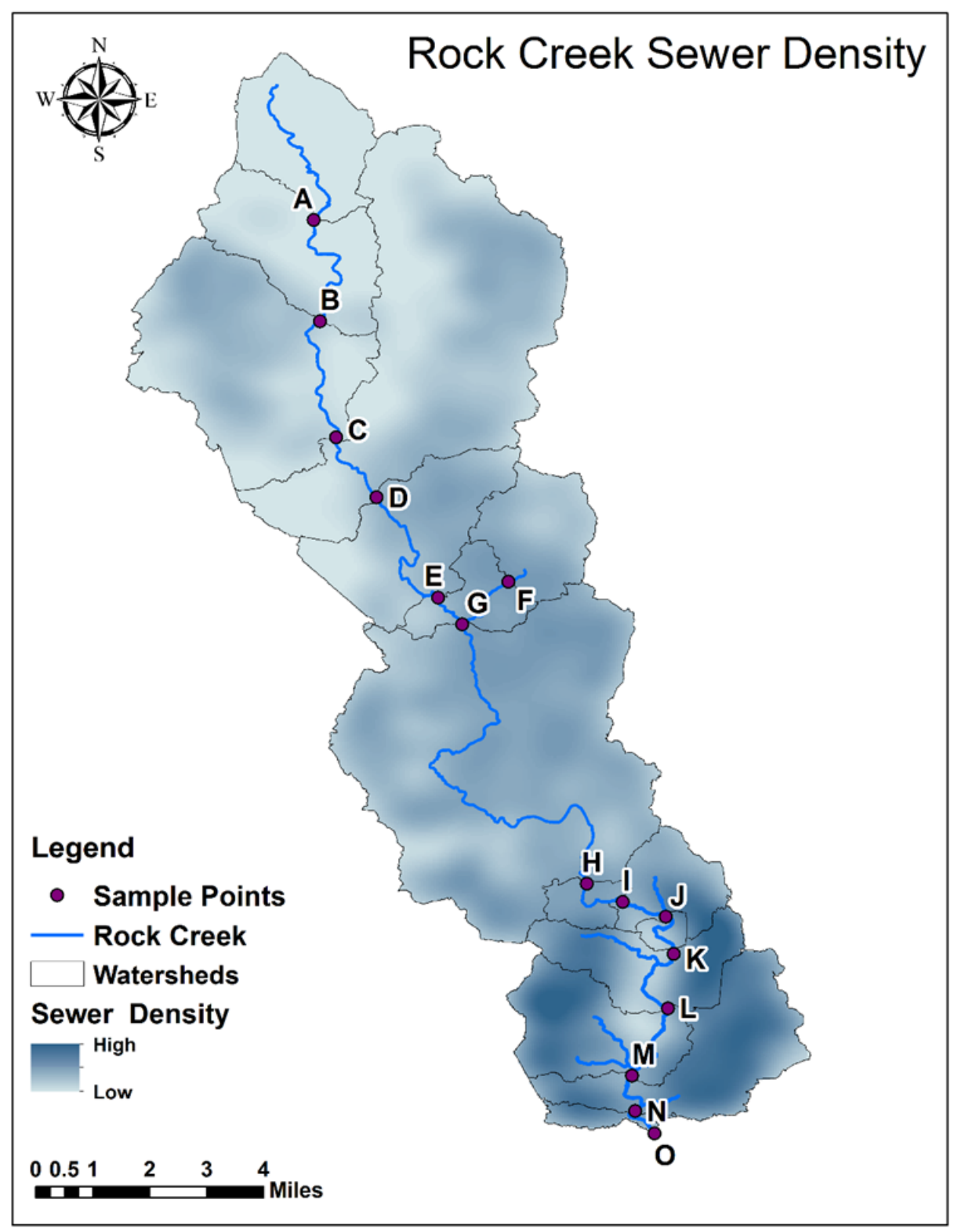




\section{ROCK CREEK STUDY}

- Mixed-use watershed

- Maryland and DC

- Rural to urban

- Sewer density and age (GIS)

- Creek sampling

- E. coli

- Nutrients ( $\mathrm{N}$ and $\mathrm{P}$ )

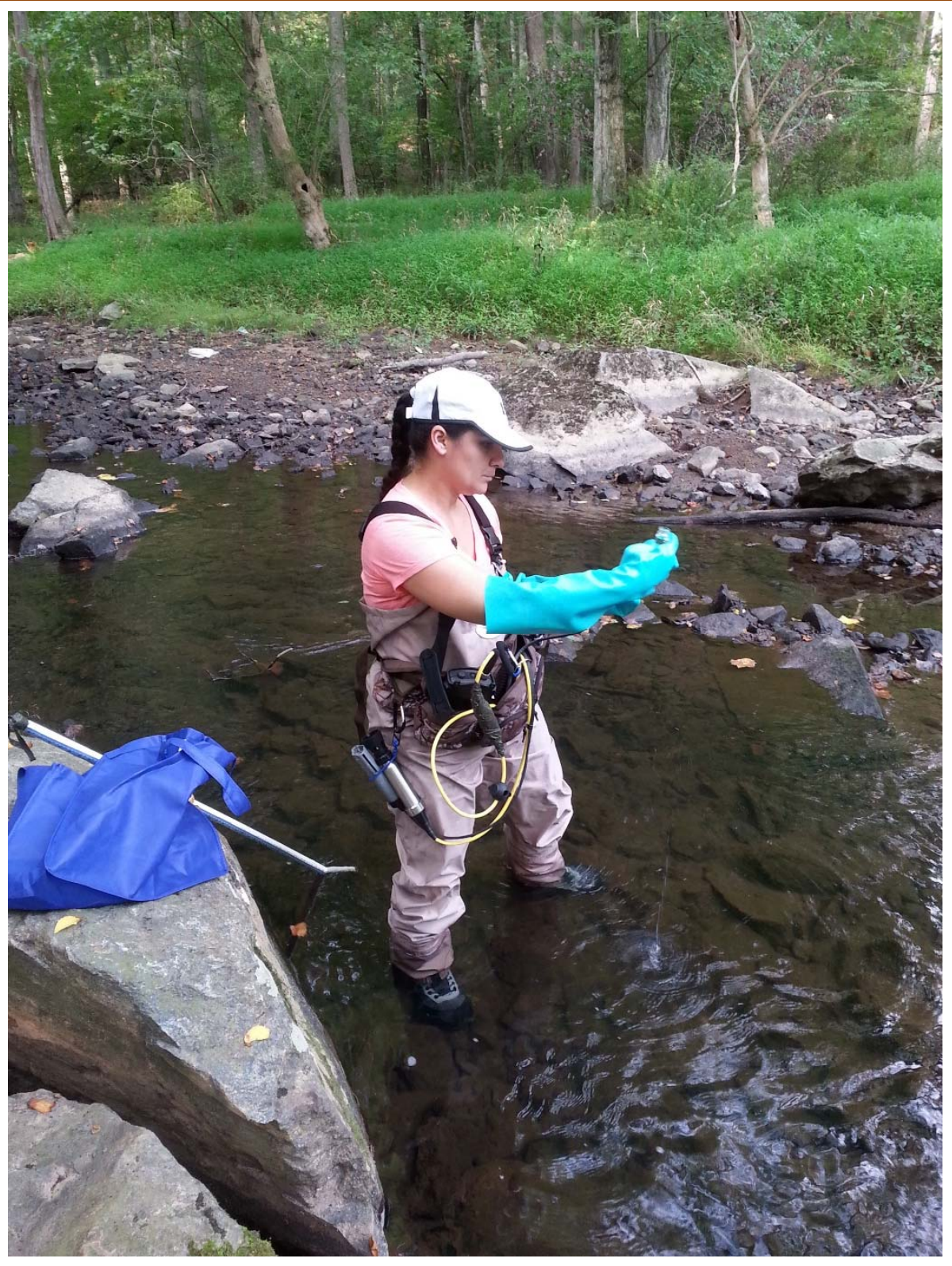




\section{ROCK CREEK RESULTS}

- High levels of E. coli

- Not correlated with sewers

- Correlation to rain events

- Multiple sources (humans, pets, wildlife)

- Nitrate correlated to land use

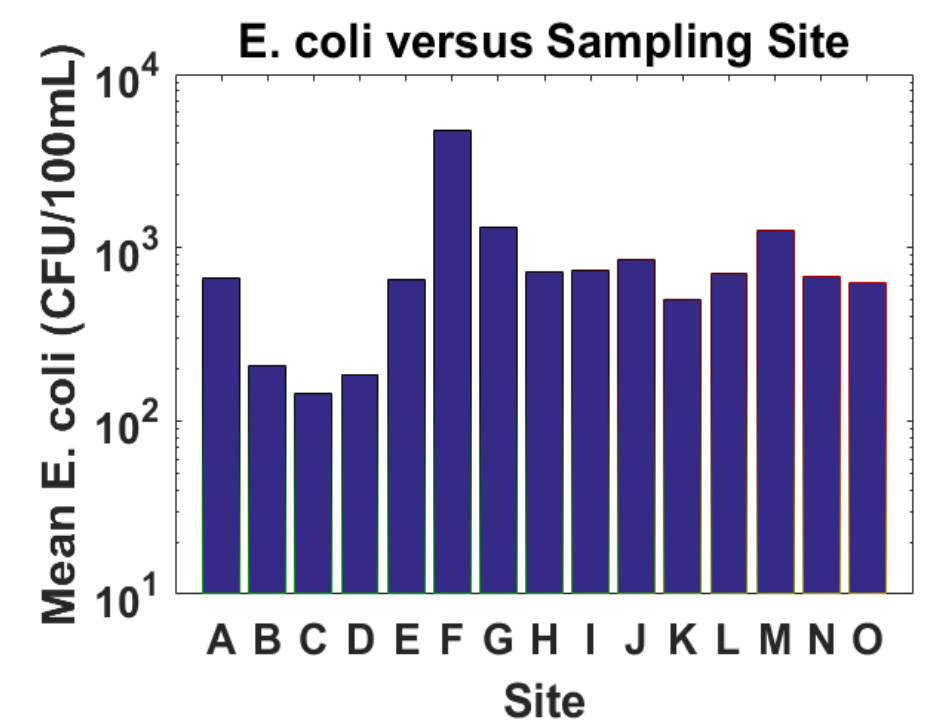

Agricultural Land Use versus Nitrate

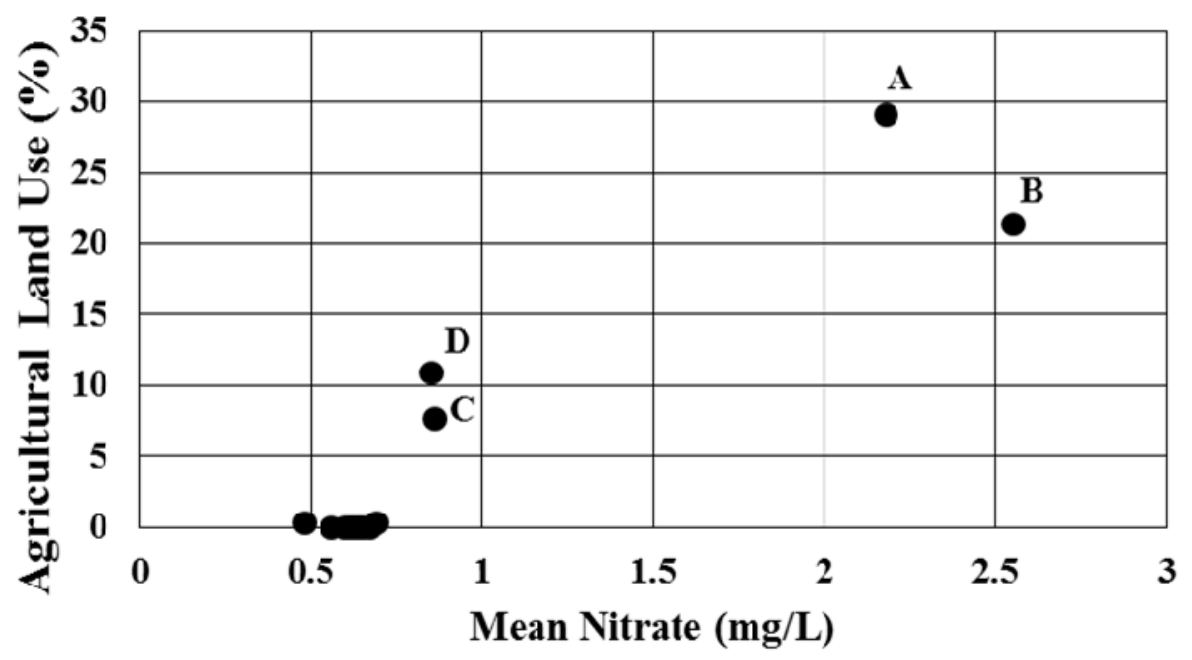




\section{CURRENT STUDY}

- Rock Creek Sampling

- Old vs. new sewers

- E. coli

- Bacteroides species

- Microbial source tracking

- Human vs. non-human

- PCR analysis

\# Human Bacteroides

\# Total Bacteroides

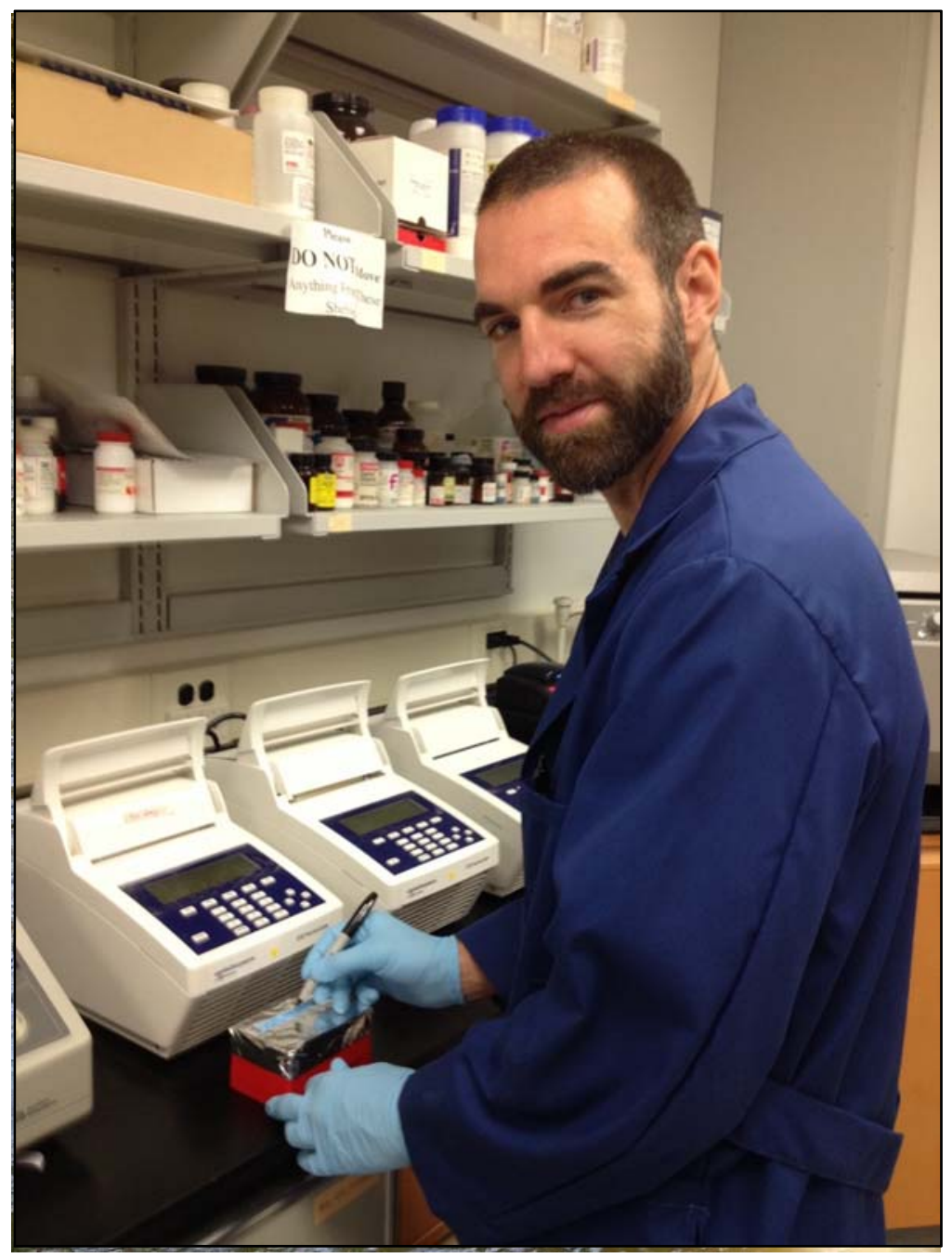




\section{NANO-TiO ${ }_{2}$ IN CONCRETE}

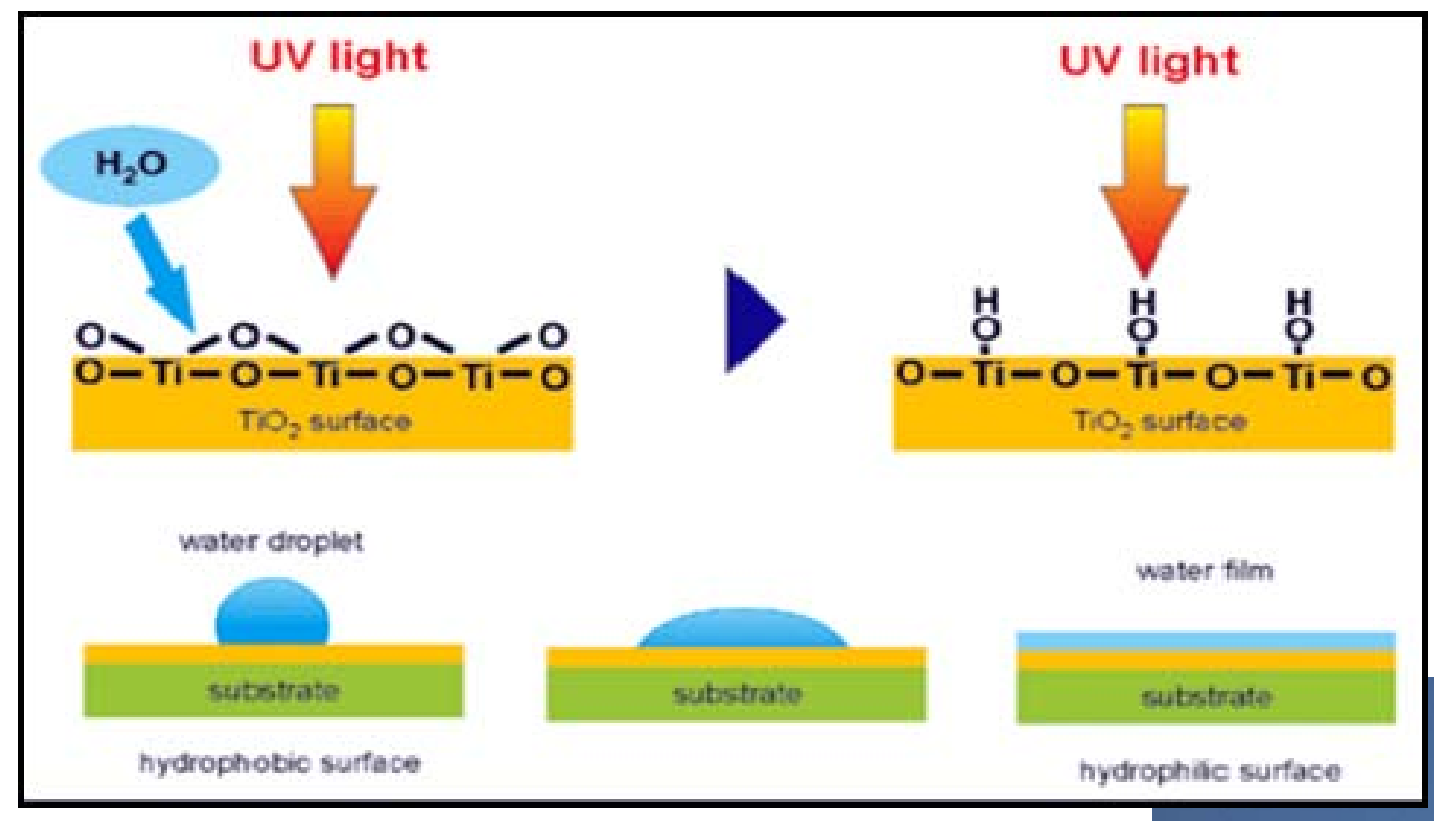

Impact of weathering?

- UV exposure

- $\mathrm{pH}$ of rain

UV Activated

- Hydrophilic surface

- Self Cleaning

- Reduces $\mathrm{NO}_{\mathrm{x}}$

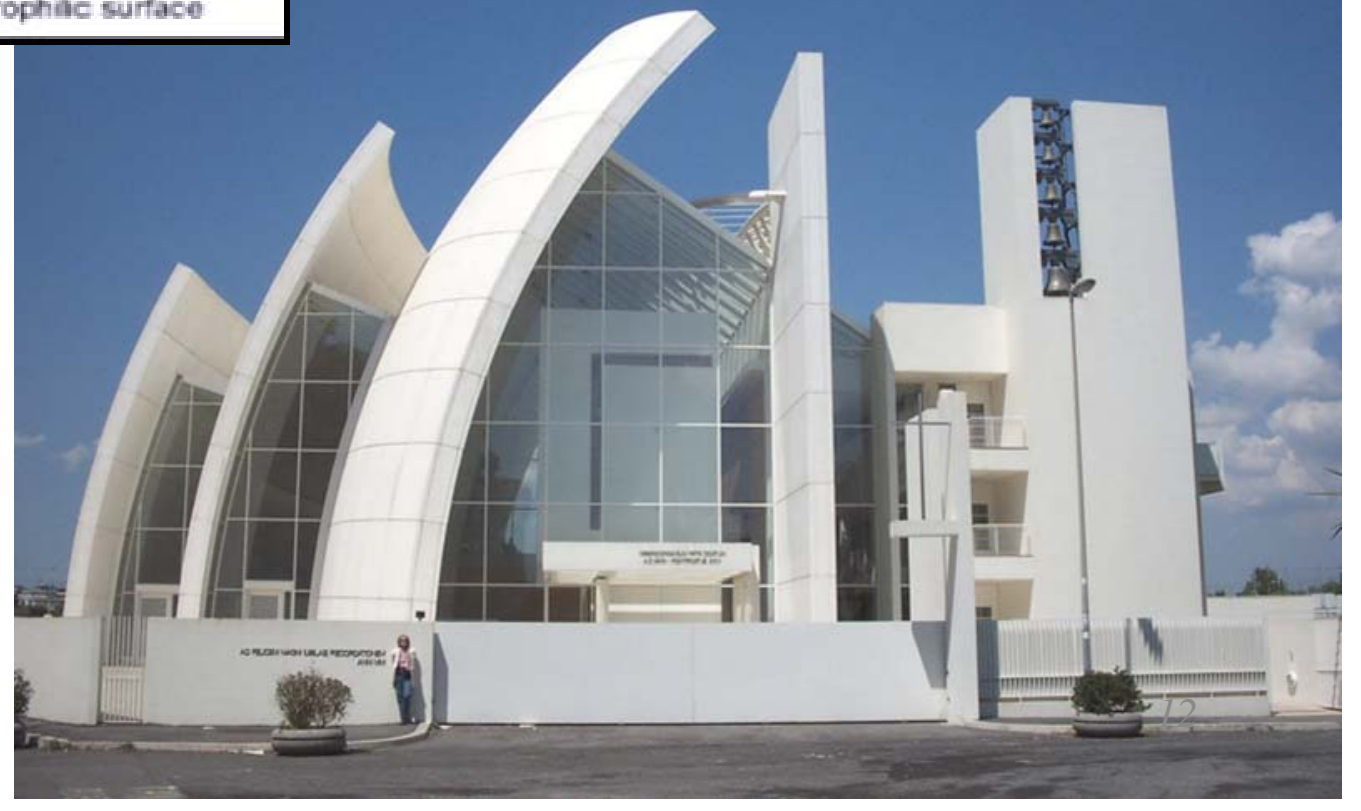




\section{METHODS}

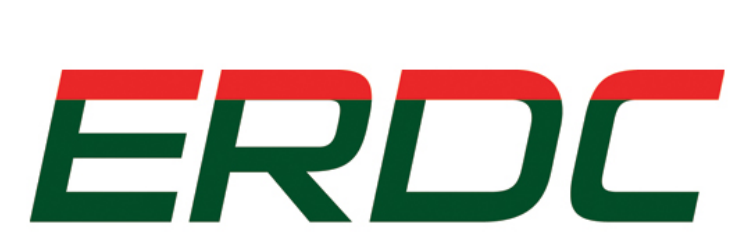

INNOVATIVE SOLUTIONS for a safer, better world
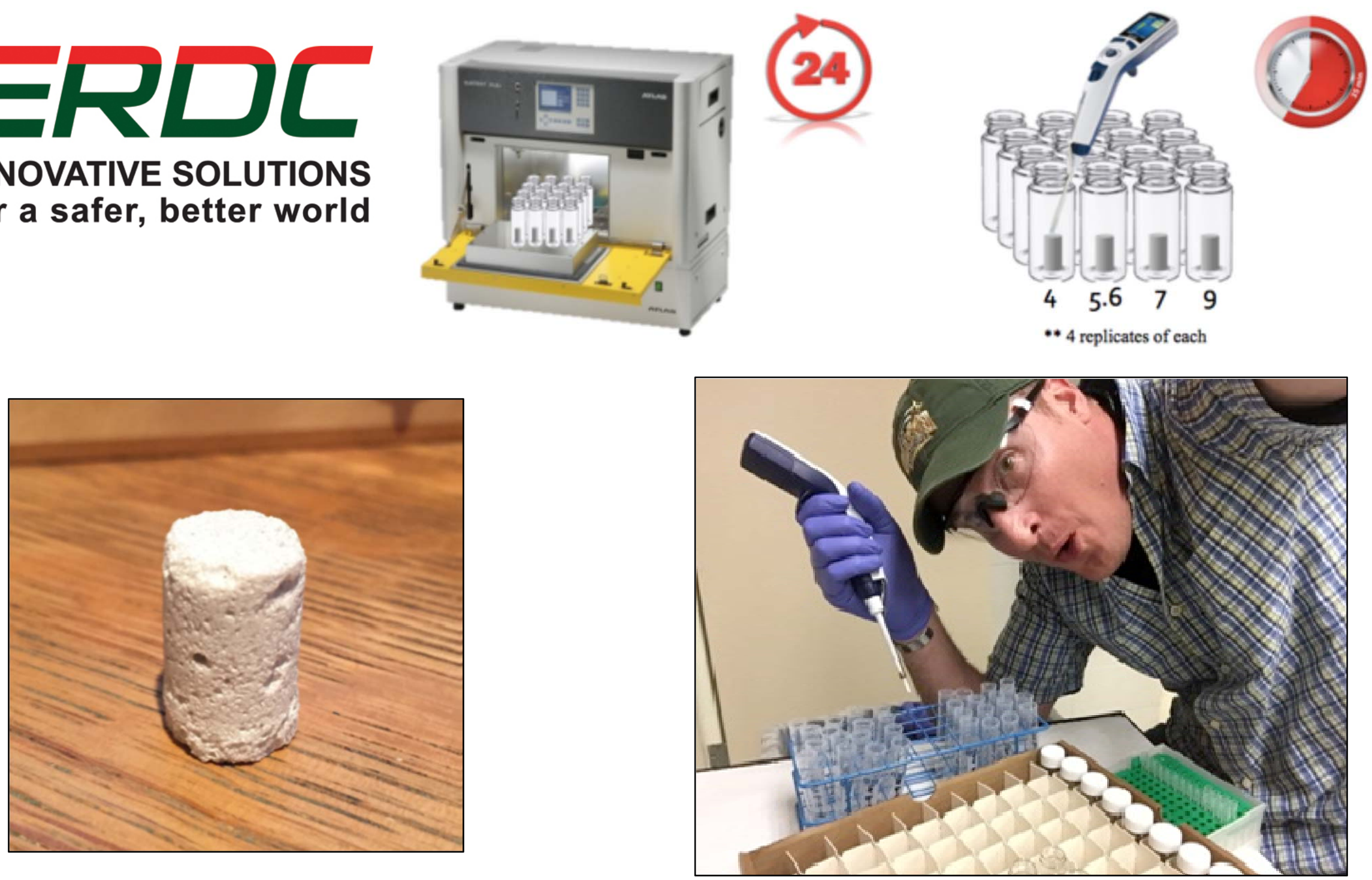


\section{RESULTS}
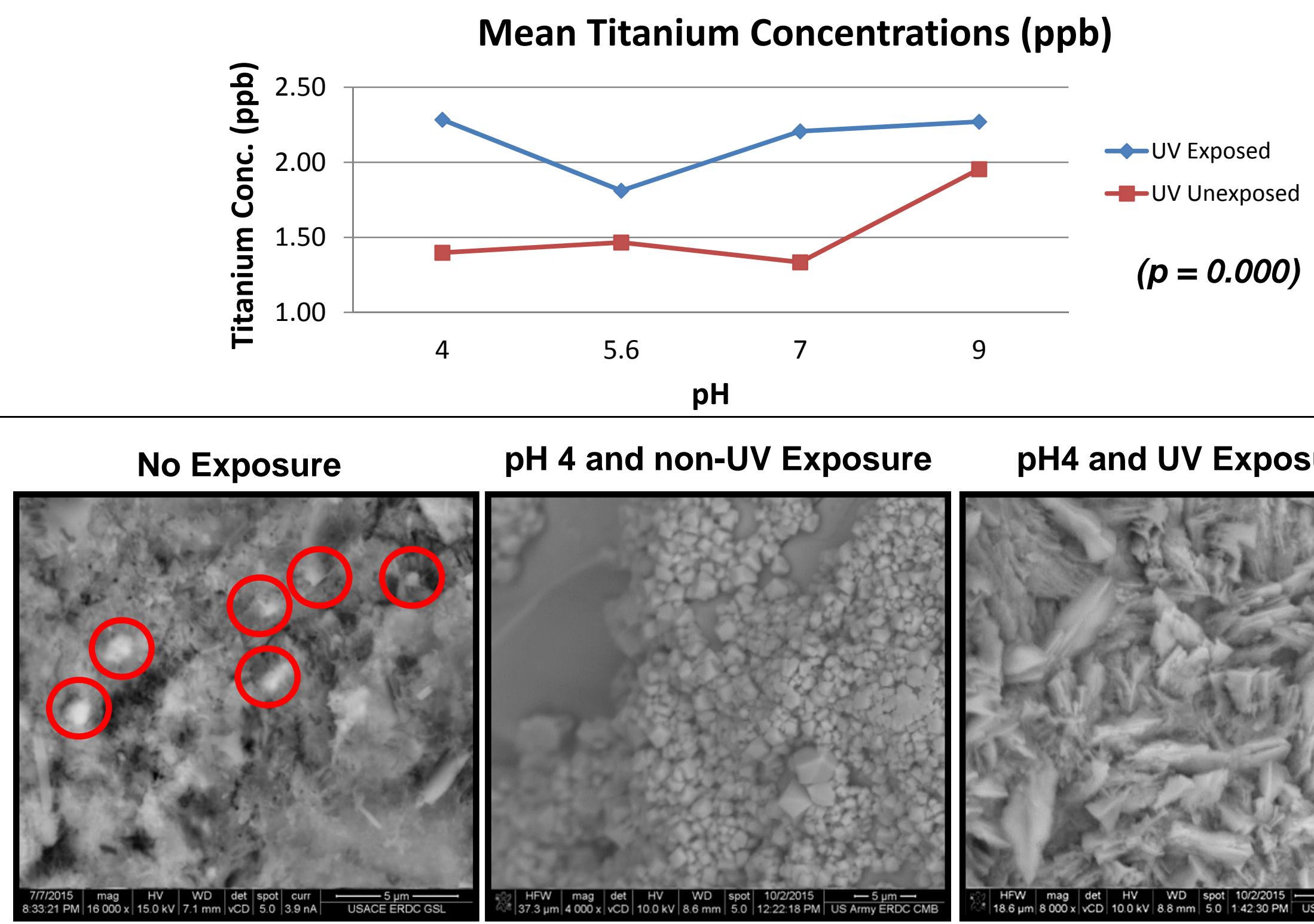

pH 4 and non-UV Exposure

pH4 and UV Exposure
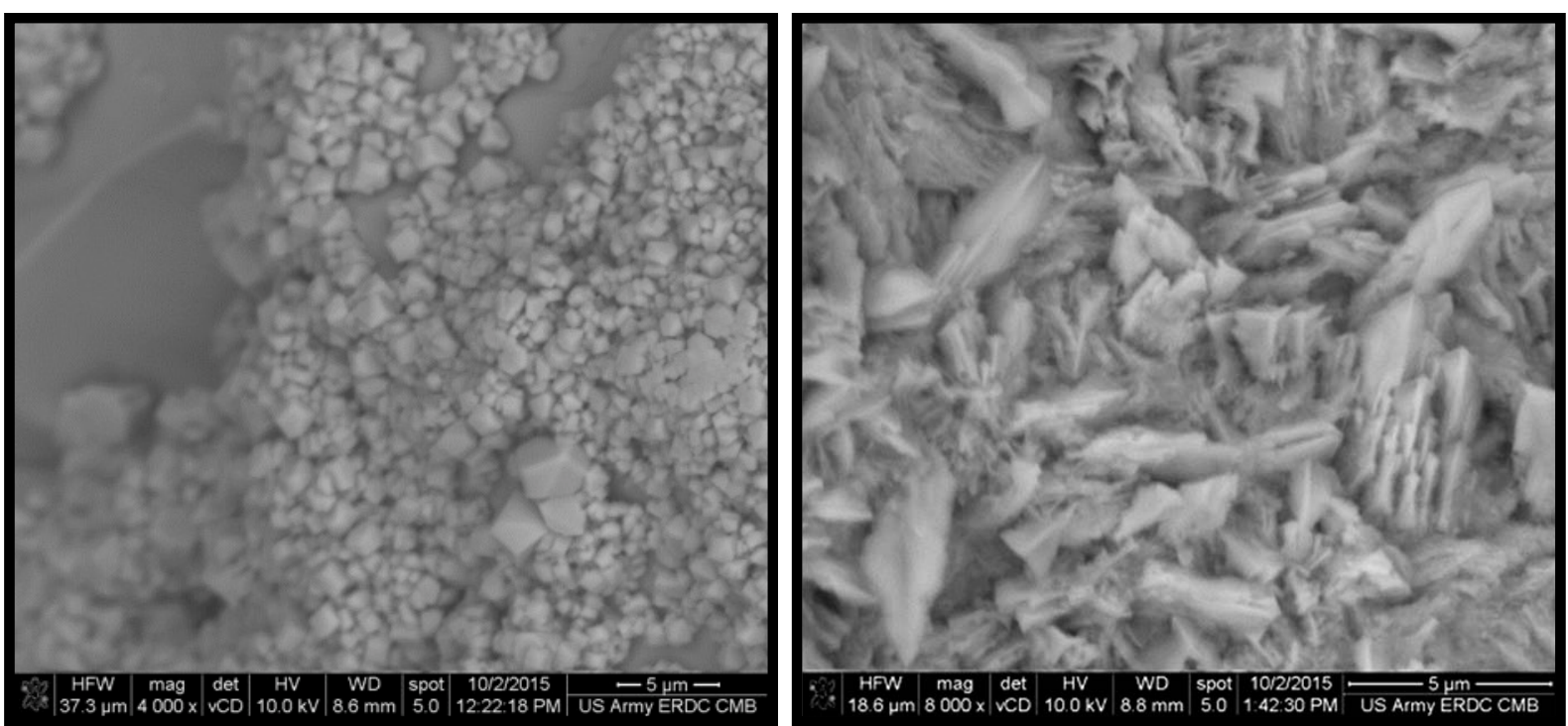


\section{CONCLUSIONS}

- New and old sources of emerging contaminants in urban environments

- Direct analysis of viruses may be optimal to detect sewer leakage

- More work required to better understand how nano- $\mathrm{TiO}_{2}$ may impact environment and human health 


\section{QUESTIONS?}

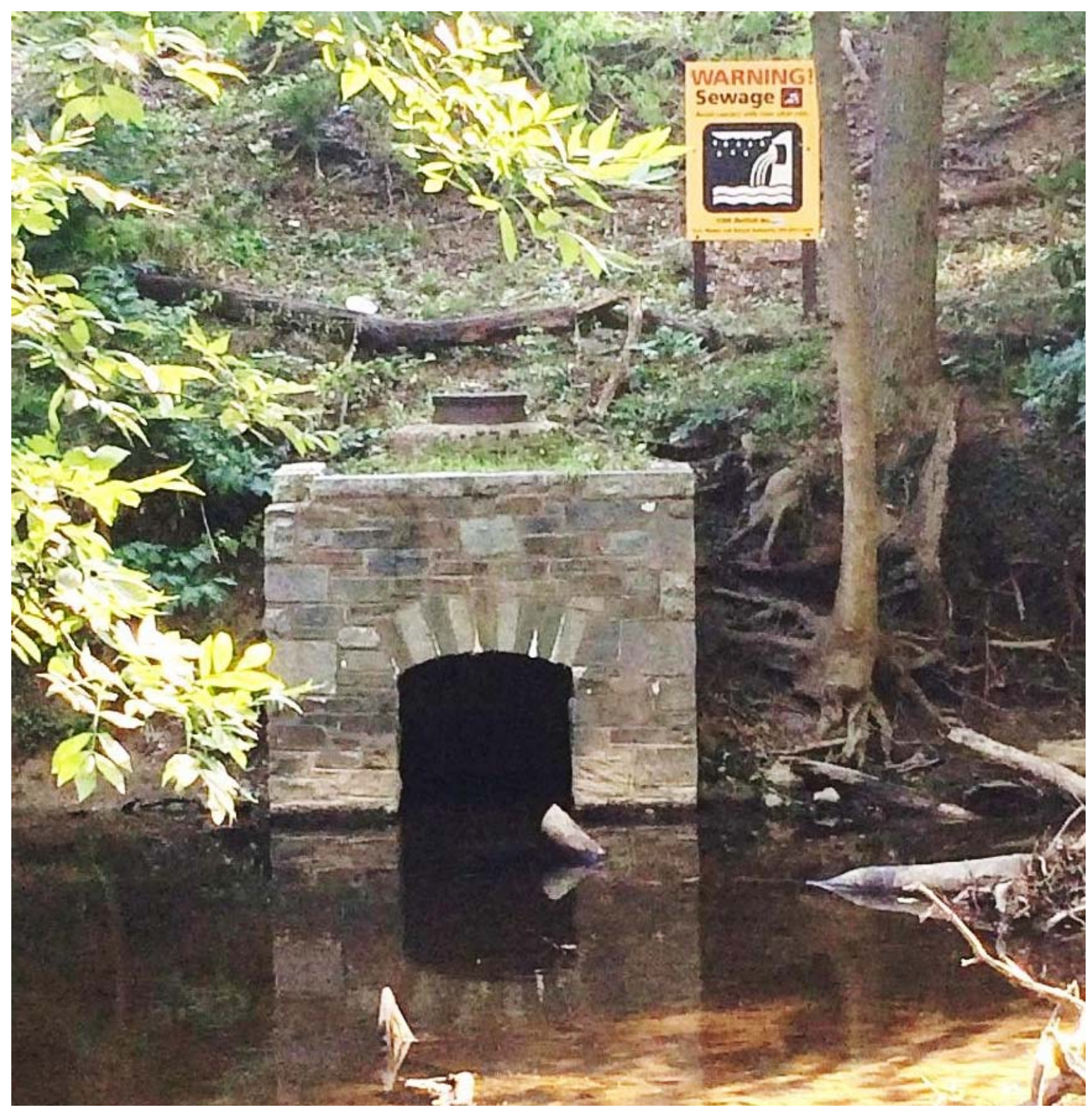

